\title{
Trends in Surgical Glaucoma Treatment in Germany Between 2006 and 2018
}

\author{
Jan Luebke $\mathbb{D}^{1,2}$ \\ Daniel Boehringer ${ }^{1,2}$ \\ Alexandra Anton ${ }^{3}$ \\ Moritz Daniel ${ }^{1,2}$ \\ Thomas Reinhard ${ }^{1,2}$ \\ Stefan Lang ${ }^{1,2}$ \\ 'Eye Center, Medical Center - University \\ of Freiburg, Freiburg, Germany; ${ }^{2}$ Faculty \\ of Medicine, University of Freiburg, \\ Freiburg, Germany; ${ }^{3}$ ADMEDICO \\ Augenzentrum, Olten, Switzerland
}

Correspondence: Jan Luebke

Eye Center, Medical Center - University

of Freiburg, Killianstrasse 5, Freiburg,

79106, Germany

Tel +4976I 27040010

Email jan.luebke@uniklinik-freiburg.de
Background/Aims: Surgical procedures in ophthalmology underlie variations over different time periods and are strongly dependent on the technical process and the invention of innovative surgical techniques. Especially, in glaucoma surgery a lot of surgical devices and techniques have been introduced during the last years. Until now, the use of these newer techniques has not been shown on a robust data basis. We herein present the numbers of different types of glaucoma surgeries performed at German hospitals between 2006 and 2018.

Methods and Design: The quality reports of hospitals in Germany from 2006 to 2018 were analyzed concerning all procedural codes for glaucoma surgery and intervention. Especially, the change in usage of "classical" and "modern" surgical techniques (MIGS: "minimally invasive glaucoma surgery") or devices was compared.

Results: The number of glaucoma procedures performed increased by $75 \%$ from 27,811 in 2006 to 48,794 in 2018. Absolute numbers of trabeculectomies, goniotomies, ab externo trabeculotomies and to a certain level cyclodestructive procedures decreased during the examined years while use of MIGS has increased in absolute and relative numbers since 2012. From 2015 a strong increase in the usage of XEN implants could be seen. Drainage implants (such as Baerveldt/Ahmed) showed stable absolute numbers over the time period covered. Absolute numbers of laser trabeculoplasty peaked in 2014 and decreased afterwards. Iridotomies and iridectomies increased by $120 \% / 248 \%$ over the whole period.

Conclusion: Our data show a trend towards the modern surgical options and especially MIGS during the recent years. Classical procedures showed a decrease in total numbers emphasized from 2013. These numbers confirm the assumption that modern glaucoma surgery is becoming more and more popular and established in German hospitals.

Keywords: glaucoma surgery, MIGS, trabeculectomy, laser trabeculoplasty

\section{Introduction}

Glaucoma is one of the leading causes of irreversible blindness. ${ }^{1}$ The disease might affect almost 80 million people in 2020 and up to 112 million people in $2040 .^{2,3}$ To date, the only ophthalmological treatment is lowering of the intraocular pressure (IOP) since elevated IOP is known to be one of the major risk factors for development and progression of the disease. ${ }^{4}$ There are different IOP-lowering treatment options: topical therapy (eye drops), laser therapy and surgery. Over the last decades, treatment options have changed and improved and especially during the last years several new surgical devices and techniques have been introduced. ${ }^{5,6}$ Especially the "MIGS" (minimally invasive glaucoma surgery) devices attracted both surgeons and patients by promising satisfying pressure-lowering capabilities with only minor surgical trauma to the eye. 
Acceptance and usage of new medical devices and treatments largely depends on the surgeon's preferences, as it has been shown for American ophthalmic surgeons. ${ }^{7,8}$ Nevertheless, the choice of treatment also depends on the medical health system in a given country itself. A changing trend for the usage of laser trabeculoplasty and filtration surgery has been shown for Australia up until 2014. ${ }^{9}$

For European countries, trends in glaucoma surgery have been published for France, Scotland, England and Wales, and Portugal but these reports only include the years until 2014, 2012 or 2015 and do not cover all different subtypes of glaucoma-related procedures. ${ }^{10-12}$ Changes in glaucoma surgery over the last years and especially since MIGS were introduced have not been published so far.

The contribution that hospitals make to the surgical treatment of patients with glaucoma in Germany can be derived from the quality reports of the Federal Joint Committee. All outpatient and inpatient surgical procedures are listed in these reports using the OPS (Operation and Procedure Code) and ICD (International Classification of Diseases). The quality reports thus provide a reliable and valid instrument for objective assessment of the quantitative surgical performance of German hospitals and have already been used for scientific analysis of ophthalmological procedures. ${ }^{13-16}$ The quality reports are publicly available. In the case of scientific use of the data there is an obligation to notify the Federal Joint Committee (G-BA). If data of the quality reports are used for scientific purposes, it must be ensured in the case of a scientific publication that they cannot be assigned to individual hospitals. The quality reports only cover medical facilities that are defined as hospitals according to German law. However, they are reliable, since they are not self-assessments, but based on accounting data.

We herein present a detailed report of the changes in different glaucoma surgeries performed in hospitals in Germany between 2006 and 2018.

\section{Methods}

The quality reports for hospitals for the years 2006 to 2018 were requested in machine-readable form (Extensible Markup-Language [XML]) at https://www.g-ba.de/institu tion/themenschwerpunkte/qualitaetssicherung/qualitaetsda ten/qualitaetsbericht/xml-daten/
For 2007, 2009 and 2011 no quality reports were available. The relevant data records were converted into a relational database.

The quality reports of the hospitals are used only partially or in extracts. For a complete, unchanged presentation of the hospital quality reports, see www.g-ba.de.

These quality reports included the pooled data of 422 German institutions in total. The total number of glaucoma surgeries performed at German hospitals and the detailed numbers for different glaucoma procedures were analyzed. Included OPS are shown in Table 1.

The OPS system has undergone several minor changes and improvements during the last years and the time period covered in our analysis. Formerly used codes were expanded (eg "filtration surgery" 5-131 was divided into differing procedures [5-131.A] which themselves were divided into usage or non-usage of adjuvant medical therapy [5-131.AB]) or additional codes were included (eg "implant surgery with anterior chamber angle outflow" 5131.61) for recently introduced procedures. Where possible, codes have been aggregated and/or summarized to enhance comparability.

In some cases, multiple codes could be used for one surgery performed. This especially includes surgical iridectomies performed during trabeculectomies. Cyclodestructive procedures included all transscleral subtypes like micropulse laser therapy and continuous wave laser. Laser trabeculoplasty includes all types of trabeculoplasty not regarding the type of laser used.

A special situation was identified for implant surgery with subconjunctival outflow (5-131.6) which covered the bigger drainage implants (Baerveldt/Ahmed) and the newer XEN implant. Since especially the number of XEN implants was of interest as it is one of the newer procedures, we assumed a steady state for the use of drainage implants (roughly 750) from 2014 on as it resembles the numbers from the preceding years. We therefore assumed that the difference between the total number of implants with subconjunctival outflow and these 750 will roughly resemble the number of XEN implants. Since only XEN45 implants were available in Germany during the time period covered we did not separate between XEN45 and XEN63.

All procedures except the XEN implant are named according to their OPS without making differences between manufacturers. As for the XEN implant an exception was needed due to the estimation we made without having a special OPS coding for it. A specific code for 
Table I All Included OPS Codes That are Assigned to Glaucoma-Related Procedures

\begin{tabular}{|c|c|}
\hline $5-13 \mid$ & Filtration surgery (unspecified) \\
\hline $5-131.0$ & Goniotrepanation or trabeculectomy \\
\hline $5-131.00$ & Without adjuvant medical therapy \\
\hline $5-|3| .0 \mid$ & With adjuvant medical therapy \\
\hline $5-|3| .0 x$ & Other \\
\hline $5-|3| . \mid$ & Scleral trepanation \\
\hline $5-13 \mid .2$ & Iridencleisis \\
\hline $5-13 \mid .3$ & Other scleral fistulation surgery \\
\hline $5-|3| .4$ & Revisional surgery after fistulation surgery \\
\hline $5-|3| .40$ & Revision of a bleb \\
\hline $5-|3| .4 \mid$ & Surgical closure after scleral fistulation surgery \\
\hline $5-13 \mid .42$ & Opening of a scleral suture \\
\hline $5-|3| .4 x$ & Other \\
\hline $5-13 \mid .5$ & Lasersclerostomy \\
\hline $5-13 \mid .6$ & (Filtration) surgery using an implant \\
\hline $5-13 \mid .60$ & ... with subconjunctival outflow \\
\hline $5-|3| .6 \mid$ & $\ldots$ with anterior chamber angle outflow \\
\hline $5-131.62$ & ... with suprachoroidal outflow \\
\hline $5-131.6 x$ & Other \\
\hline $5-|3| .7$ & Trabeculotomy \\
\hline $5-|3| .8$ & Goniotomy \\
\hline $5-|3| \cdot x$ & Other \\
\hline $5-|3| . y$ & Not specified \\
\hline $5-133$ & Improving aqueous humor circulation \\
\hline $5-133.0$ & Surgical iridectomy \\
\hline $5-133.1$ & Trabeculotomy \\
\hline $5-133.2$ & Goniotomy \\
\hline $5-133.3$ & Laser trabeculoplasty \\
\hline $5-133.4$ & Gonioplasty or iridoplasty via laser \\
\hline $5-133.5$ & Cyclodialysis \\
\hline $5-133.6$ & Laser iridotomy \\
\hline $5-133.7$ & Trabecular aspiration \\
\hline $5-133.8$ & Intraocular trabeculotomy \\
\hline $5-133.80$ & Via laser \\
\hline $5-133.8 \mid$ & Via electroablation \\
\hline $5-133.8 x$ & Other \\
\hline $5-133.9$ & Trabecular shunt implantation \\
\hline $5-133 . x$ & Other \\
\hline $5-133 . y$ & Not specified \\
\hline $5-132$ & $\begin{array}{l}\text { Lowering of the intraocular pressure through ciliary body } \\
\text { surgery }\end{array}$ \\
\hline $5-132.0$ & Not specified \\
\hline $5-132.1$ & Cyclocryotherapy \\
\hline $5-132.2$ & Cyclophotocoagulation \\
\hline $5-132.20$ & Surgically \\
\hline $5-132.21$ & Endoscopically \\
\hline $5-132.22$ & Transsclerally \\
\hline $5-132.2 x$ & Other \\
\hline $5-132 . x$ & Other \\
\hline $5-132 . y$ & Not specified \\
\hline $5-134$ & Non-filtrating surgery \\
\hline
\end{tabular}

(Continued)
Table I (Continued).

\begin{tabular}{|l|l|}
\hline $5-134.0$ & Viscocanalostomy \\
$5-134.00$ & Without adjuvant medical therapy \\
$5-134.01$ & With adjuvant medical therapy \\
$5-134.1$ & Deep sclecrectomy \\
$5-134.10$ & Without adjuvant medical therapy \\
$5-134.11$ & With adjuvant medical therapy \\
$5-134.2$ & Viscocanaloplasty \\
$5-134 . x$ & Other \\
$5-134 . y$ & Not specified \\
\hline
\end{tabular}

these implants was introduced in 2019. The Preserflo Microshunt was not fully introduced in Germany in 2018 so only very minor numbers of these implants should be included. We therefore did not separate between the XEN implant and the Preserflo Microshunt.

We included the following OPS in the subgroup of MIGS: 5-131.61, 5-131.62, 5-133.8, 5-133.80, 5133.81 and 5-133.9. Since the XEN implant is usually seen as a mixture of minimal invasive procedures and filtrations surgery we did not include it in the term MIGS as it is used in the following (what is in accordance with the guidelines of the European Glaucoma Society). ${ }^{17}$

Canalostomy might include ab interno canaloplasty but also other techniques to open Schlemm's canal ab interno (such as trabeculotomy). The according OPS code could be used for several procedures.

All graphs were created and calculations were performed with the Software R. ${ }^{18}$

\section{Results}

The different types of surgeries showed a huge variation over the analyzed time period.

The total number of glaucoma procedures including laser trabeculoplasty and iridotomy increased from 27,811 in 2006 to 48,794 in 2018 , which resembles an increase of about $75 \%$.

Laser trabeculoplasty increased from 667 in 2006 up to its peak in 2014 of 3677 and then declined to a number of 2736 in 2018 and accounted for up to $8.24 \%$ of all performed glaucoma procedures at its peak in 2012.

Iridotomies and iridectomies increased over the whole examined period from $1415 / 1688$ to $3120 / 4187$, which resembles an increase of about $120 \% / 248 \%$ and accounts for almost 15\% of all performed procedures in 2018 .

MIGS could only be tracked from 2012 on but then increased from only 56 up to 5589 in 2018 and then 
accounted for more than $11 \%$ of all procedures in our data. The annual growth rate for these procedures was especially high in the first years and settled at around 16$35 \%$ for the last years (growth rates: 2013: 858\%, 2014: 66\%, 2015: 218\%, 2016: 16\%, 2017: 35\%, 2018: 29\%). Similar growth rates could be found for the estimated number of XEN implants.

The rate of trabeculectomies and filtration surgery in total decreased slightly over the years after a peak in 2008 (9557; 25.54\%), especially during the more recent years from 2015 on $(7275 / 16.83 \%$ in 2015 to $5844 / 11.98 \%$ in 2018). Of these procedures, an increasing part was performed with additional medical antifibrotic treatment (eg Mitomycin C). In 2018, 5.3\% of filtration surgeries were performed without and $92.1 \%$ were performed with additional antifibrotic treatment; $2.6 \%$ were not specified. In 2006, 30.7\% were performed without and 53.9\% were performed with antifibrotic treatment while $15.4 \%$ were not specified. Bleb-revisional surgery that accounts for revision after trabeculectomy/goniotomy as well as after XEN implantation increased slightly over the years but tripled in total in 2018 compared to 2006.

Cyclodestructive procedures decreased in numbers from more than $10,000 \quad(36.1 \%$ of all procedures in that year) in 2006 down to 5241 in 2015 and increased again in the recent years. In 2017 and 2018, cyclodestructive procedures were the most frequently performed glaucoma surgery in German hospitals with a relative proportion of $17.38 \%$ in 2018 .

The number of ( $\mathrm{ab}$ externo) trabeculotomies performed decreased especially from 2015 on. Compared to 2014 there was a drop from 2163 to 767 , which equals a decrease of around $65 \%$.

Table 2 shows the numbers of all subgroups of different surgeries for the different years while Table 3 shows a more detailed view on the MIGS procedures.

In relation to the number of total surgeries performed in 2006 and 2018, cyclodestructive procedures were the most often performed surgeries but were topped by filtration surgery in the years 2013 to 2016. As already stated, MIGS gained from 2012 until 2018 accounting for more than $11 \%$ of total glaucoma procedures performed in 2018 .

Besides viscocanaloplasty, non-penetrating surgical procedures accounted for only minor proportions of total surgeries during the included timeframe. Deep sclerectomies were constantly below 1000 procedures per year and accounted for $1.59 \%$ of the total in 2018 and $2.31 \%$ in
2006. Viscocanaloplasty steadily increased from 2012 $(809 / 1.86 \%)$ to $2281(4.67 \%)$ in 2018.

For chosen surgeries and different subgroups, plots for the numbers of surgeries over the covered time period are shown in Figures 1,Figures 2. MIGS procedures are shown divided into different types in Figure 3.

\section{Discussion}

The aim of this study was to analyze the rates of different glaucoma procedures in Germany over the last years especially in regard of newer procedures like MIGS and their comparison to more classical surgical approaches.

At first, there has to be stated that the German medical system allows surgical treatments in both inpatient and outpatient ways regardless of whether the treatment takes place in a hospital. The numbers we present in this study do only reflect patients treated in institutions which provide inpatient treatment (but do as well offer outpatient treatment). Facilities that only perform outpatient procedures are not covered. Nevertheless, trends in changes of surgical rates over time might reflect the total changes well.

In total, we saw an increase of about $75 \%$ for all glaucoma procedures from 2006 to 2018 . This can partly be explained by the increase in outpatient treatments like laser iridotomy or laser trabeculoplasty but the surgical procedures increased in total number too during that time period. Other European countries (United Kingdom and Portugal) found similar trends during earlier time periods. $^{11,12}$ In a Canadian report ranging from 1992 until 2012 surgical rates did not increase in a similar way, although laser trabeculoplasty was used in increasing numbers. ${ }^{19}$ The need for increasing numbers of procedures might in part be explained by the aging society in Germany and other developed countries. Since glaucoma is primarily a disease of the elderly, we might see a further increase of procedure rates during the next years. Another reason for increasing total numbers might be better ways of diagnosing glaucoma and therefore a raised need in treatment. Advances in diagnostic tools like OCT (optical coherence tomography) and improved glaucoma screening patterns might have led to a higher rate of diagnosed and treatment-needing patients. $^{20,21}$ Another potential reason for increased numbers in procedures could be the modern understanding of target IOP and therefore the need for lowering IOP lower than $21 \mathrm{mmHg}$ as, for example, in normal tension glaucoma. Lower IOP values can usually be more easily and 
reliable be achieved with surgeries compared to local therapy.

Additionally, we cannot rule out that patients underwent multiple procedures and with increasing surgical options there might be a trend to more procedures performed on a single patient.

Interestingly the rates of iridotomies and iridectomies increased over the almost entire period. Usually being performed in patients having a narrow angle situation (mostly iridotomy) or even a glaucoma attack (mostly iridectomy), these increasing numbers might lead to the question of whether the rates of narrow angle situations increased in a similar way. In 2012, Day et al reported a prevalence of angle closure glaucoma in Europe of $0.4 \%$ for people 40 years or older while earlier estimations assumed rates ranging from 0.1 to $0.25 \%{ }^{22}$ This might explain the rates of increased treatment in these patients. Especially, iridotomy has recently been shown to be a useful prophylactic treatment in narrow angle situations. $^{23}$ Kerr et al showed a similar increase for iridotomy rates in Australia until 2014 while surgical iridectomies did not increase similarly. ${ }^{9}$ The aging society could have an influence on these numbers as well due to a thicker lens with increasing cataract and a more narrow chamber angle. It has to be taken into account, though, that surgical iridectomies might have been coded in addition to the code for other surgeries such as trabeculectomy.

Rates of laser trabeculoplasty (LT) as a non-surgical treatment showed the highest numbers during a period from 2012 to 2014 and then decreased again. Selective laser trabeculoplasty (SLT) as an alternative to the formerly performed argon laser trabeculoplasty (ALT) was first described in a clinical study in 1998 by Latina et al. ${ }^{24}$ A publication that might have led the way for increasing popularity of SLT was probably the study by Nagar et al published in 2005 that compared SLT with the use of latanoprost. ${ }^{25}$ With an increasing number of studies that proved the effect of SLT and further distribution of needed equipment, the increasing rates of SLT in Germany for the following years might be explained. Kerr et al reported similar increases for LT figures in Australia from 2005 until 2014, as did Szigiato et al for Ontario, Canada. ${ }^{9,19}$ These studies did not cover the time period from 2014 on, in which we saw a decrease of laser trabeculoplasty numbers again. One possible explanation could be a "natural" decrease due to the situation of LT not being a new procedure anymore. It might also be a result of its IOPlowering effect that was not as strong as many ophthalmologists might have hoped for and therefore performed less SLT procedures. Another one might be that a lot of glaucoma patients might have been treated with ALT or more recently SLT and did not undergo a repeat procedure, which at least for SLT would be possible. Nevertheless, the LT numbers from 2015 on were still higher than they were in 2006 and 2008. After the highly relevant LiGHT study was published in 2019, in which an IOP-controlling and economic comparison between SLT and a latanoprost therapy was made, we might see another increase in SLT procedure numbers in the next years. ${ }^{26}$

Concerning the numbers of glaucoma implants, a slight increase until 2013 and from then on a huge rise in implantations performed could be found. Apart from the bigger glaucoma drainage implants (Baerveldt/Ahmed), especially the smaller implants such as the iStent, CyPass and the XEN implant were introduced during the recent years. Just recently, the PreserFlo shunt was introduced but due to its novelty it should not affect the implant numbers in this study. The first year in which the code for trabecular bypass shunt implantation (iStent) was used was 2013, and the code for suprachoroidal drainage (CyPass) was first used in 2016. These implant devices all promised sufficient lowering of the intraocular pressure with a lower risk profile and a less invasive surgery compared to the classical surgical methods which has not been proven true for all implants, as the CyPass was withdrawn from the market in 2018.

The first XEN implants were used in 2013 but just recently (2019) a suitable code that differentiates between the bigger drainage devices and the XEN implant was introduced. The numbers of XEN implantations we calculated therefore is just an estimate but should reflect the development of its use sufficiently.

It is difficult to compare these implant numbers since the newer procedures were not covered in studies reporting on glaucoma surgeries so far. Barbosa-Breda et al covered the timeframe until 2015 and included bigger drainage devices for the last of these years and reported an increase in drainage device usage in Portugal as well as Murphy et al found for the years from 2006 to 2012 in Scotland, England and Wales. ${ }^{11,12}$ Bron et al found a similar trend until 2014 for France. ${ }^{10}$ Our data show a similar increase for glaucoma implants until 2014 but raise a lot more in the years after. From 2013 until 2018 the implant numbers increased by eight times. Since XEN implants were first used in Germany in 2013 these developments for the implant numbers could at least in part be explained by that introduction. Chang et al presented the procedure 
Table 2 Numbers (and Percentages of Total) for Types of Surgery and Grouped Surgeries

\begin{tabular}{|c|c|c|c|c|c|c|c|c|}
\hline Viscocanaloplasty & $\begin{array}{r}\text { Deep } \\
\text { Sclerectomy }\end{array}$ & Canalostomy & Goniotomy & Trabeculotomy & $\begin{array}{r}\text { Cyclodestructive } \\
\text { Surgery }\end{array}$ & Implants & $\begin{array}{r}\text { Bleb } \\
\text { Revisions }\end{array}$ & $\begin{array}{r}\text { With } \\
\text { Adjuvant } \\
\text { Treatment }\end{array}$ \\
\hline & $643(2.31 \%)$ & 81 (0.29\%) & $167(0.6 \%)$ & 718 (2.58\%) & $10,040(36.1 \%)$ & 269 (0.97\%) & $\begin{array}{r}966 \\
(3.47 \%)\end{array}$ & $\begin{array}{r}376 \mid \\
(13.52 \%)\end{array}$ \\
\hline & 715 (1.91\%) & 297 (0.79\%) & $148(0.4 \%)$ & 752 (2.01\%) & 11,909 (31.83\%) & $\begin{array}{r}379 \\
(1.01 \%)\end{array}$ & $\begin{array}{r}1611 \\
(4.31 \%)\end{array}$ & $\begin{array}{r}5983 \\
(15.99 \%)\end{array}$ \\
\hline & 623 (1.64\%) & $580(1.52 \%)$ & 129 (0.34\%) & 1302 (3.42\%) & II,559 (30.34\%) & $\begin{array}{r}708 \\
(1.86 \%)\end{array}$ & $\begin{array}{r}1938 \\
(5.09 \%)\end{array}$ & $\begin{array}{r}637 \mid \\
(16.72 \%)\end{array}$ \\
\hline 809 (1.86\%) & 833 (1.91\%) & 552 (I.27\%) & $189(0.43 \%)$ & 1601 (3.68\%) & II,720 (26.91\%) & 828 (1.9\%) & $\begin{array}{r}2298 \\
(5.28 \%)\end{array}$ & $\begin{array}{r}7743 \\
(17.78 \%)\end{array}$ \\
\hline 1166 (2.6\%) & 852 (1.9\%) & 425 (0.95\%) & I8I (0.4\%) & 2098 (4.67\%) & 5778 (12.86\%) & $\begin{array}{r}1047 \\
(2.33 \%)\end{array}$ & $\begin{array}{r}2554 \\
(5.69 \%)\end{array}$ & $\begin{array}{r}7485 \\
(16.66 \%)\end{array}$ \\
\hline $1630(3.48 \%)$ & 963 (2.06\%) & $393(0.84 \%)$ & 379 (0.8I\%) & $2163(4.62 \%)$ & 6245 (13.33\%) & $\begin{array}{r}1614 \\
(3.45 \%)\end{array}$ & $\begin{array}{r}2482 \\
(5.3 \%)\end{array}$ & $\begin{array}{r}7148 \\
(15.26 \%)\end{array}$ \\
\hline I 403 (3.25\%) & $922(2.13 \%)$ & $25 \mathrm{I}(0.58 \%)$ & $378(0.87 \%)$ & 767 (I.77\%) & $524 \mid(12.12 \%)$ & $\begin{array}{r}2917 \\
(6.75 \%)\end{array}$ & $\begin{array}{r}2458 \\
(5.69 \%)\end{array}$ & $\begin{array}{r}6633 \\
(15.34 \%)\end{array}$ \\
\hline 1582 (3.78\%) & 951 (2.27\%) & $220(0.53 \%)$ & 179 (0.43\%) & 722 (1.73\%) & 5331 (12.74\%) & $\begin{array}{r}3990 \\
(9.54 \%)\end{array}$ & $\begin{array}{r}2437 \\
(5.83 \%)\end{array}$ & $\begin{array}{r}5763 \\
(13.78 \%)\end{array}$ \\
\hline $2194(4.51 \%)$ & 790 (1.62\%) & $162(0.33 \%)$ & $313(0.64 \%)$ & 870 (1.79\%) & $7530(15.46 \%)$ & $\begin{array}{r}6426 \\
(13.2 \%)\end{array}$ & $\begin{array}{r}3170 \\
(6.51 \%)\end{array}$ & $\begin{array}{r}6172 \\
(12.67 \%)\end{array}$ \\
\hline $228 \mid(4.67 \%)$ & 776 (1.59\%) & $206(0.42 \%)$ & 482 (0.99\%) & 771 (I.58\%) & 8482 (17.38\%) & $\begin{array}{r}7968 \\
(16.33 \%)\end{array}$ & $\begin{array}{r}3105 \\
(6.36 \%)\end{array}$ & $\begin{array}{r}5384 \\
(11.03 \%)\end{array}$ \\
\hline
\end{tabular}

Abbreviations: LTP, laser trabeculoplasty; LPI, laser peripheral iridotomy; MIGS, minimal invasive glaucoma surgery (including trabecular stents, intraocular trabeculotomy via laser or electroablation, suprachoroidal shunts); Drainage implants, Baerveldt/Ahmed implant, including XEN; XEN, estimated value (see Methods section); Filtration surgery. not including XEN implant; Implants, all implantable glaucoma devices including drainage implants and MIGS implants.

preferences of glaucoma surgeons if they had to adopt the role of the patient and showed that especially the XEN implant was highly popular. ${ }^{7}$ To examine this trend better and in a more reliable way we will have to wait until more detailed surgical codes are established for longer time periods.

MIGS procedures in our data included other surgical options besides implants, namely the trabeculotomy

Table 3 Numbers (and Percentages of Total) for Total Count of Surgeries and MIGS (Minimal Invasive Glaucoma Surgery) and Different Types of MIGS

\begin{tabular}{|c|c|c|c|c|c|c|c|}
\hline Year & Total & MIGS & $\begin{array}{l}\text { Chamber } \\
\text { Angle } \\
\text { Shunt }\end{array}$ & $\begin{array}{l}\text { Suprachoroidal } \\
\text { Shunt }\end{array}$ & $\begin{array}{l}\text { Intraocular } \\
\text { Trabeculotomy }\end{array}$ & $\begin{array}{l}\text { Intraocular } \\
\text { Trabeculotomy } \\
\text { (via Laser) }\end{array}$ & $\begin{array}{l}\text { Intraocular } \\
\text { Trabeculotomy (via } \\
\text { Electroablation) }\end{array}$ \\
\hline 2006 & 27,811 & & & & \multirow{10}{*}{$\begin{array}{r}56(0.13 \%) \\
68(0.15 \%) \\
125(0.27 \%)\end{array}$} & \multirow[b]{7}{*}{$55(0.13 \%)$} & \multirow[b]{7}{*}{ I I 20 (2.59\%) } \\
\hline 2008 & 37,418 & & & & & & \\
\hline 2010 & 38,093 & & & & & & \\
\hline 2012 & 43,554 & $56(0.13 \%)$ & & & & & \\
\hline 2013 & 44,923 & $537(1.2 \%)$ & 469 (1.04\%) & & & & \\
\hline 2014 & 46,839 & 894 (1.91\%) & 769 (1.64\%) & & & & \\
\hline 2015 & 43,235 & 2849 (6.59\%) & 1674 (3.87\%) & & & & \\
\hline 2016 & 41,835 & $3313(7.92 \%)$ & 1904 (4.55\%) & 347 (0.83\%) & & $5 \mathrm{I}(0.12 \%)$ & 1011 (2.42\%) \\
\hline 2017 & 48,699 & 4499 (9.24\%) & 2570 (5.28\%) & 814 (1.67\%) & & $104(0.21 \%)$ & $1011(2.08 \%)$ \\
\hline 2018 & 48,794 & 5589 (II.45\%) & 3331 (6.83\%) & I I 22 (2.3\%) & & $133(0.27 \%)$ & $1003(2.06 \%)$ \\
\hline
\end{tabular}




\begin{tabular}{|c|c|c|c|c|c|c|c|c|c|c|c|}
\hline $\begin{array}{r}\text { Without } \\
\text { Adjuvant } \\
\text { Treatment }\end{array}$ & $\begin{array}{r}\text { Filtration } \\
\text { Surgery }\end{array}$ & XEN* & $\begin{array}{l}\text { Drainage } \\
\text { Implants }\end{array}$ & Iridectomy & LPI & LTP & MIGS & $\begin{array}{r}\text { Total - LTPI } \\
\text { LPI }\end{array}$ & LTP/LPI & Total & Year \\
\hline $\begin{array}{r}2139 \\
(7.69 \%)\end{array}$ & $\begin{array}{r}6972 \\
(25.07 \%)\end{array}$ & & $\begin{array}{r}269 \\
(0.97 \%)\end{array}$ & $\begin{array}{r}1688 \\
(6.07 \%)\end{array}$ & $\begin{array}{r}1415 \\
(5.09 \%)\end{array}$ & $\begin{array}{r}667 \\
(2.4 \%)\end{array}$ & & $\begin{array}{r}25,729 \\
(92.51 \%)\end{array}$ & $\begin{array}{r}2082 \\
(7.49 \%)\end{array}$ & 27,811 & 2006 \\
\hline $\begin{array}{r}1058 \\
(2.83 \%)\end{array}$ & $\begin{array}{r}9557 \\
(25.54 \%)\end{array}$ & & $\begin{array}{r}379 \\
(1.01 \%)\end{array}$ & $\begin{array}{r}1951 \\
(5.21 \%)\end{array}$ & $\begin{array}{r}|52| \\
(4.06 \%)\end{array}$ & $\begin{array}{r}157 \mid \\
(4.2 \%)\end{array}$ & & $\begin{array}{r}34,326 \\
(91.74 \%)\end{array}$ & $\begin{array}{r}3092 \\
(8.26 \%)\end{array}$ & 37,418 & 2008 \\
\hline 891 (2.34\%) & $\begin{array}{r}8798 \\
(23.1 \%)\end{array}$ & & $\begin{array}{r}708 \\
(1.86 \%)\end{array}$ & $\begin{array}{r}1508 \\
(3.96 \%)\end{array}$ & $\begin{array}{r}1965 \\
(5.16 \%)\end{array}$ & $\begin{array}{r}2991 \\
(7.85 \%)\end{array}$ & & $\begin{array}{r}33,137 \\
(86.99 \%)\end{array}$ & $\begin{array}{r}4956 \\
(13.01 \%)\end{array}$ & 38,093 & 2010 \\
\hline 719 (1.65\%) & $\begin{array}{r}8534 \\
(19.59 \%)\end{array}$ & & 828 (1.9\%) & 1828 (4.2\%) & $\begin{array}{r}2159 \\
(4.96 \%)\end{array}$ & $\begin{array}{r}3590 \\
(8.24 \%)\end{array}$ & $56(0.13 \%)$ & $\begin{array}{r}37,805 \\
(86.8 \%)\end{array}$ & $\begin{array}{r}5749 \\
(13.2 \%)\end{array}$ & 43,554 & 2012 \\
\hline $572(1.27 \%)$ & $\begin{array}{r}8068 \\
(17.96 \%)\end{array}$ & & $\begin{array}{r}578 \\
(1.29 \%)\end{array}$ & $\begin{array}{r}3437 \\
(7.65 \%)\end{array}$ & $\begin{array}{r}2119 \\
(4.72 \%)\end{array}$ & $\begin{array}{r}3363 \\
(7.49 \%)\end{array}$ & 537 (1.2\%) & $\begin{array}{r}39,44 \mathrm{I} \\
(87.8 \%)\end{array}$ & $\begin{array}{r}5482 \\
(12.2 \%)\end{array}$ & 44,923 & 2013 \\
\hline 654 (I.4\%) & $\begin{array}{r}8040 \\
(17.17 \%)\end{array}$ & $95(0.2 \%)$ & 845 (1.8\%) & $\begin{array}{r}3620 \\
(7.73 \%)\end{array}$ & $\begin{array}{r}2252 \\
(4.81 \%)\end{array}$ & $\begin{array}{r}3677 \\
(7.85 \%)\end{array}$ & $\begin{array}{r}894 \\
(1.91 \%)\end{array}$ & $\begin{array}{r}40,910 \\
(87.34 \%)\end{array}$ & $\begin{array}{r}5929 \\
(12.66 \%)\end{array}$ & 46,839 & 2014 \\
\hline 503 (1.16\%) & $\begin{array}{r}7275 \\
(16.83 \%)\end{array}$ & $\begin{array}{r}493 \\
(1.14 \%)\end{array}$ & $\begin{array}{r}1243 \\
(2.87 \%)\end{array}$ & $\begin{array}{r}3769 \\
(8.72 \%)\end{array}$ & $\begin{array}{r}2388 \\
(5.52 \%)\end{array}$ & $\begin{array}{r}3183 \\
(7.36 \%)\end{array}$ & $\begin{array}{r}2849 \\
(6.59 \%)\end{array}$ & $\begin{array}{r}37,664 \\
(87.11 \%)\end{array}$ & $\begin{array}{r}557 \mid \\
(\mid 2.89 \%)\end{array}$ & 43,235 & 2015 \\
\hline $423(1.01 \%)$ & $\begin{array}{r}6467 \\
(15.46 \%)\end{array}$ & $\begin{array}{r}989 \\
(2.36 \%)\end{array}$ & $\begin{array}{r}1739 \\
(4.16 \%)\end{array}$ & $\begin{array}{r}3616 \\
(8.64 \%)\end{array}$ & $\begin{array}{r}2220 \\
(5.31 \%)\end{array}$ & $\begin{array}{r}2431 \\
(5.81 \%)\end{array}$ & $\begin{array}{r}3313 \\
(7.92 \%)\end{array}$ & $\begin{array}{r}37,184 \\
(88.88 \%)\end{array}$ & $\begin{array}{r}4651 \\
(11.12 \%)\end{array}$ & 41,835 & 2016 \\
\hline 335 (0.69\%) & $\begin{array}{r}6675 \\
(13.71 \%)\end{array}$ & $\begin{array}{r}2292 \\
(4.71 \%)\end{array}$ & $\begin{array}{r}3042 \\
(6.25 \%)\end{array}$ & $\begin{array}{r}3710 \\
(7.62 \%)\end{array}$ & $\begin{array}{r}2597 \\
(5.33 \%)\end{array}$ & $\begin{array}{r}2713 \\
(5.57 \%)\end{array}$ & $\begin{array}{r}4499 \\
(9.24 \%)\end{array}$ & $\begin{array}{r}43,389 \\
(89.1 \%)\end{array}$ & $\begin{array}{r}5310 \\
(10.9 \%)\end{array}$ & 48,699 & 2017 \\
\hline 309 (0.63\%) & $\begin{array}{r}5844 \\
(11.98 \%)\end{array}$ & $\begin{array}{r}2765 \\
(5.67 \%)\end{array}$ & $\begin{array}{r}3515 \\
(7.2 \%)\end{array}$ & $\begin{array}{r}4187 \\
(8.58 \%)\end{array}$ & $\begin{array}{r}3120 \\
(6.39 \%)\end{array}$ & $\begin{array}{r}2736 \\
(5.61 \%)\end{array}$ & $\begin{array}{r}5589 \\
(11.45 \%)\end{array}$ & 42,938 (88\%) & 5856 (12\%) & 48,794 & 2018 \\
\hline
\end{tabular}

performed intraocularly via laser (excimer laser trabeculoplasty, ELT) or via electroablation (Trabectome). Our data show an enormous increase for all of these MIGS procedures in total from the years 2013 on, although the trabeculotomy ab interno showed a nearly steady state after a big increase from 2014 to 2015 which might be explained by the introduction of the new code for trabeculotomy via electroablation in 2015. The huge decrease of trabeculotomy in total might be explained with the emerging of other MIGS procedures introduced around that time. The total increase in MIGS procedures and modern surgery reflects the assumed trend in modern glaucoma surgery. ${ }^{27,28}$ Until now, these assumed trends could not be reflected in real numbers. Our data show that this assumption of favoring newer procedures or MIGS is a major reason for the increase of the total number of performed glaucoma surgeries.

Nonpenetrating surgical procedures other than canaloplasty (and canalostomy) accounted for only minor proportions of total surgeries. Canaloplasty itself as a procedure somewhat in between the classical options such as trabeculectomy and the modern MIGS increased steadily over the years, which might reflect the trend from more invasive surgery to procedures that promise less complications. These numbers cannot be compared to other countries due to the lack of published data on this procedure.

Presenting the numbers, we separated between "modern" and "classical" surgical procedures. Classical procedures included mainly types of surgery that have been available and established for a longer time and did not undergo changes in the way they are performed. Cyclodestructive procedures were the most frequently performed glaucoma surgery until 2013. From then until 2016 their use decreased and trabeculectomy was the most frequently used surgical procedure, but the rate of cyclodestructive procedures increased again in the years 2017 and 2018 and in these years accounted for the most performed group of glaucoma procedures in German hospitals. This is somewhat surprising due to the assumed popularity of MIGS but it has to be taken 


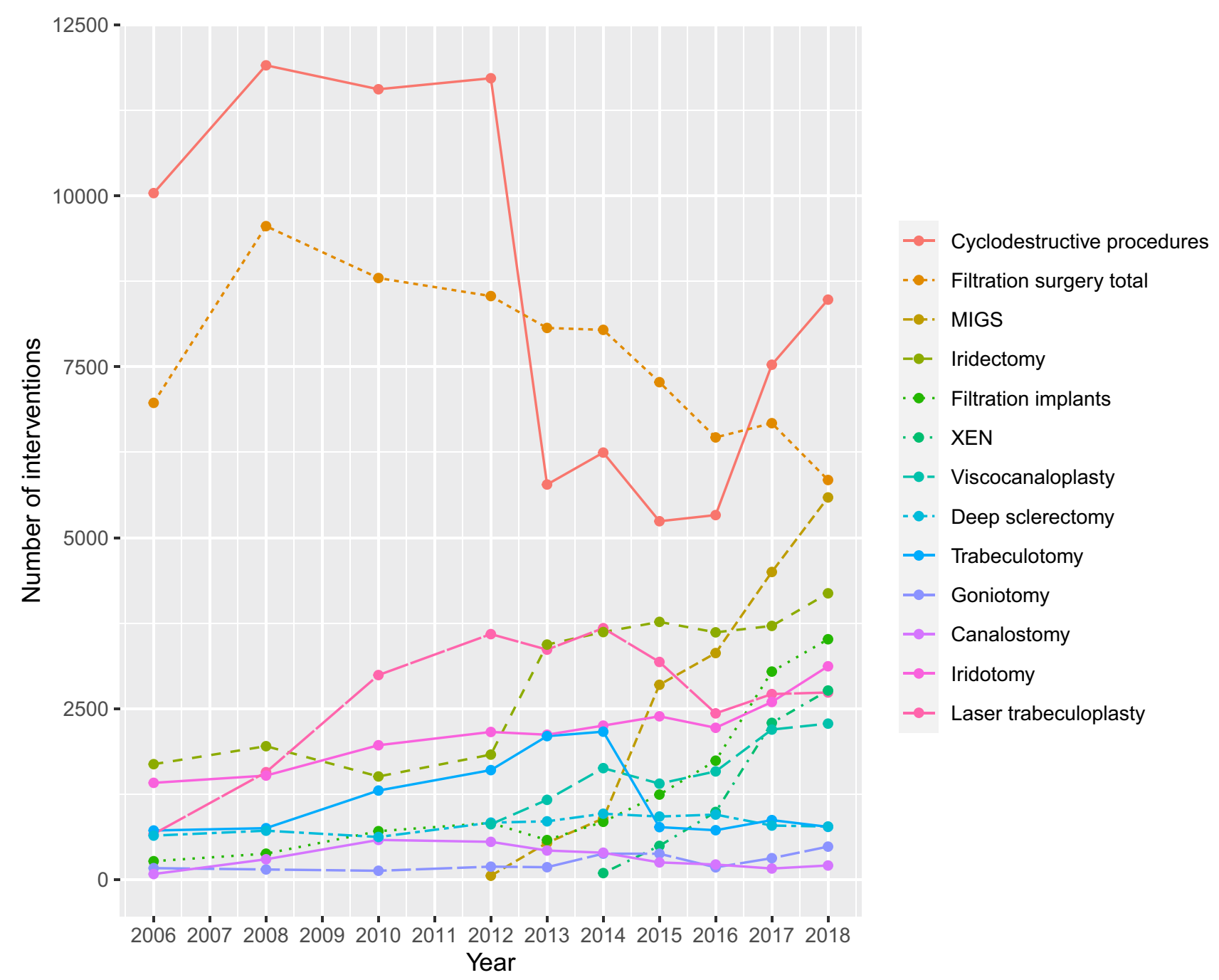

Figure I All glaucoma surgeries plotted over the examined time period. Filtration surgery total includes classical filtration surgery such as trabeculectomy and goniotrepanation without implants. Filtration implants include drainage devices such as Baerveldt and Ahmed but also XEN.

into account that preferably MIGS could have been performed in outpatient non-hospital settings which is unusual for cyclodestructive procedures in Germany. A possible explanation for this decrease from 2013 could have been the emerging MIGS and an adaption of these by surgeons, and therefore changing preferences. An important point could also be the different approach to the lowering of the IOP these modern procedures established. The procedures like the Trabectome, the CyPass or the iStent performed through clear cornea cuts offered different possibilities to surgeons after failed surgeries like trabeculectomy. Prior to this innovation, the surgical options besides transconjunctival approaches were limited to cyclodestructive procedures. This resembles similar trends from other countries until 2012, 2013 or 2014. ${ }^{9,10,12}$ Barbosa-Breda et al did not find similar numbers for Portugal. ${ }^{11}$ Especially in England,
Scotland and Wales, higher rates for cyclodestructive procedures than for trabeculectomies could be found as well. ${ }^{12}$

The decrease of trabeculotomy performed via the classical ab externo approach after 2014 might be explained with the introduction of MIGS as well. Sparing conjunctiva but still targeting the trabecular meshwork as is possible with the Trabectome or the iStent might have been a more attractive option than performing classical trabeculotomy.

Especially interesting are the developments of the classical trabeculectomy and its newer variant, the XEN implant. The decrease of the numbers of trabeculectomies performed from 2008 on intensified from 2014 on, the year after the XEN implant was introduced to the German market and other MIGS emerged. The XEN implant is supposed to be a surgical option for patients who usually would undergo trabeculectomy so this decrease can probably be explained 


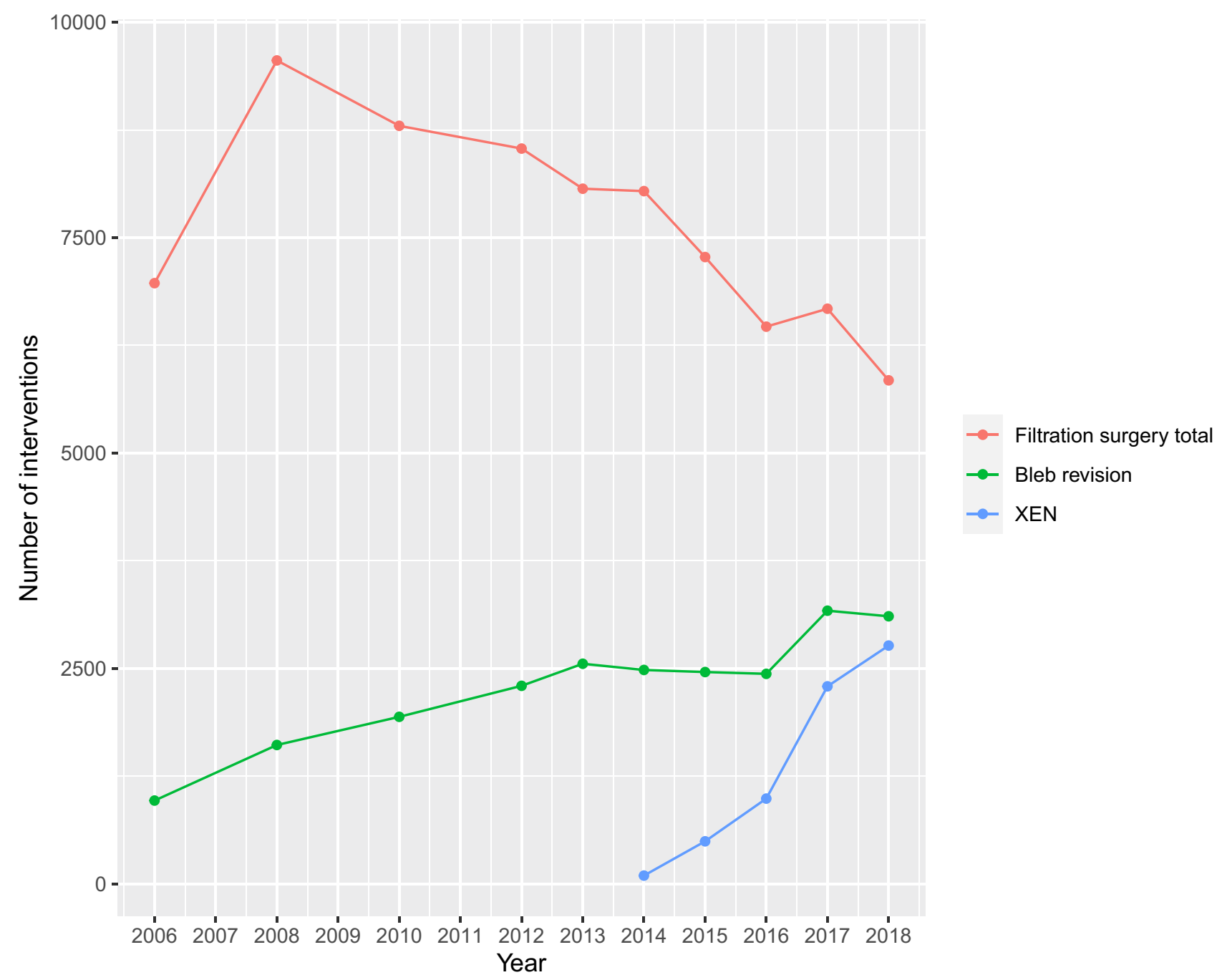

Figure 2 Filtration surgery total (including trabeculectomy and goniotrepanation but not including XEN or drainage implants) compared to XEN and revisional surgery after filtration surgery.

by the implant's introduction in $2013 .{ }^{29}$ Chang et al showed that surgeons preferred the XEN implant for themselves if they were patients. ${ }^{7}$ The numbers of performed trabeculectomies decreased in France and Portugal in a similar way while the numbers that Kerr et al presented for Australia showed a decrease until 2006 and a slight increase after that until 2014..$^{9-11}$ Summarizing, this trend towards a decrease is especially consistent in European countries. The rates of revision surgery after filtration procedures or implant surgery increased slightly especially in the recent years (2017 and 2018). It has been shown that XEN implantation goes along with a higher rate of bleb needling or revision surgery and this increase is probably explained by increased usage of these implants. ${ }^{30,31}$

Another potential factor that might affect the numbers and rates of procedures performed is the role that advertising has for newer procedures compared to older ones. Latest procedures are well advertised and recommended within the group of ophthalmologists and ophthalmic surgeons but might lose their place in the spotlight to newer procedures after a while and therefore be performed less often.

Last but not least, the cost of procedures or devices themselves might affect changing trends for different types of surgeries. Interestingly, usage of MIGS (that usually are more expensive) rose and classical surgical procedures like trabeculectomy (that is way less expensive) declined in usage numbers during our analyzed time period. This might on the other hand be a strength of the German health care system that offers surgeons the choice between different procedures without too much financial pressure on the individual decision. Besides the financial influence, there might be 


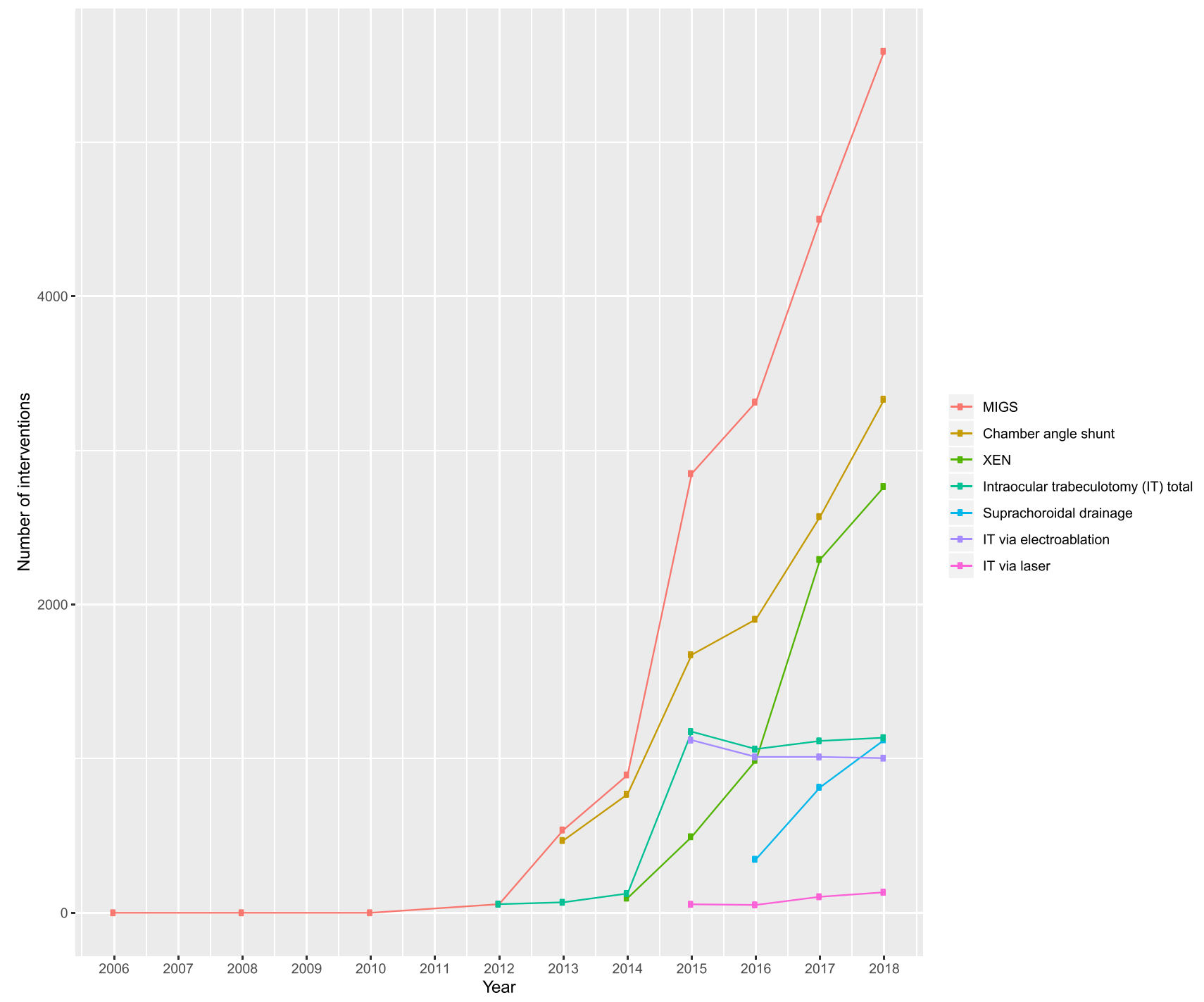

Figure 3 XEN compared to different types of MIGS and MIGS in total.

a changing trend for surgical glaucoma procedures depending on the need and intensity of follow-up examinations. This could, for example, explain why trabeculectomy might have become less popular compared to modern procedures that are less demanding in follow-up workups.

Especially, the years 2020 and 2021 might see another change in treatment rates of different types of glaucoma surgeries due to the pandemic situation. It might be possible that total treatment numbers decline and that there could be a trend towards surgical procedures that do not need extensive follow-up examinations to not have too many appointments at hospitals and not put the patients at risk for getting infected. This topic might be very interesting to be addressed in the upcoming years.

\section{Conclusion}

Our data show that glaucoma procedures performed in German hospitals increased a lot in the time period from 2006 to 2018. Especially from 2013 on, the so-called MIGS and newer drainage devices such as the XEN implant were used a lot while classical procedures like trabeculotomy via an external approach, cyclodestructive procedures and trabeculectomy decreased in numbers.

The assumed trend towards a minimal invasive glaucoma surgery can therefore be confirmed for German hospitals.

\section{Limitations of This Study}

Although reflecting a huge part of the German health system, hospitals are not the only facilities where glaucoma procedures are performed. Private practitioners perform surgeries on an outpatient basis and especially 
laser procedures and MIGS might be preferred in these settings. In Germany, classical surgeries are usually performed on an inpatient basis so the conclusion that there is a trend towards modern ways of glaucoma surgery might even be underestimated. We cannot give information on the proportion of surgeries performed outside of hospitals. Usually, mostly standard cataract surgeries are performed on an outpatient basis. The German healthcare system and its way of paying ophthalmologists for surgical procedures favors inpatient procedures especially for more complicated surgeries that have a somewhat higher risk for complications. This is one of the reasons why especially the classical glaucoma procedures such as trabeculectomy are mostly performed on an inpatient basis. We therefore think that especially this portion of our data are representative. But our data might underestimate the trend towards modern procedures since especially MIGS might be performed in combination with cataract surgery on an outpatient basis and therefore would not have been accounted for in our data. Another limitation is that the data we provide are based on the partly insufficient code system for defining the performed surgery and their change during the examined period. Especially, the numbers for XEN implants are estimates based on an assumed steady state for the use of drainage implants. Especially, newer procedures are not adequately reflected in the code system and have to be "fitted" into the existing codes.

\section{Data Sharing Statement}

Data from the G-BA are publically available.

\section{Ethics Approval}

Not required since publication of data from the G-BA is permitted generally.

\section{Acknowledgments}

The article processing charge was funded by the BadenWürttemberg Ministry of Science, Research and Art and the University of Freiburg in the funding programme Open Access Publishing and the Freunde der UniversitätsAugenklinik Freiburg e.V.

\section{Funding}

There is no funding to report.

\section{Disclosure}

The authors reported no conflicts of interest for this work.

\section{References}

1. Jonas JB, Aung T, Bourne RR, et al. Glaucoma. Lancet. 2017;390 (10108):2183-2193. doi:10.1016/S0140-6736(17)31469-1

2. Quigley HA. The number of people with glaucoma worldwide in 2010 and 2020. Br J Ophthalmol. 2006;90(3):262-267. doi:10.1136/ bjo.2005.081224

3. Tham Y-C, Li X, Wong TY, et al. Global prevalence of glaucoma and projections of glaucoma burden through 2040. Ophthalmology. 2014;121(11):2081-2090. doi:10.1016/j.ophtha.2014.05.013

4. Gordon MO, Kass MA. What we have learned from the Ocular Hypertension Treatment Study. Am J Ophthalmol. 2018;189:xxivxxvii. doi:10.1016/j.ajo.2018.02.016

5. Quigley HA. 21st century glaucoma care. Eye. 2019;33(2):254-260. doi:10.1038/s41433-018-0227-8

6. Higginbotham EJ, Alexis D. Is newer necessarily better? The evolution of incisional glaucoma surgery over the last 100 years. Am J Ophthalmol. 2018;191:xxv-xxix. doi:10.1016/j.ajo.2018.04.009

7. Chang TC, Vanner EA, Parrish RK. Glaucoma surgery preferences when the surgeon adopts the role of the patient. Eye. 2019;1-7. doi:10.1038/s41433-019-0452-9

8. Vinod K, Gedde SJ, Feuer WJ, et al. Practice preferences for glaucoma surgery: a survey of the American Glaucoma Society. J Glaucoma. 2017;26(8):687. doi:10.1097/IJG.0000000000000720

9. Kerr NM, Kumar HK, Crowston JG, Walland MJ. Glaucoma laser and surgical procedure rates in Australia. Br J Ophthalmol. 2016;100 (12):1686-1691. doi:10.1136/bjophthalmol-2015-307994

10. Bron AM, Mariet A-S, Benzenine E, et al. Trends in operating room-based glaucoma procedures in France from 2005 to 2014: a Nationwide Study. Br J Ophthalmol. 2017;101(11):1500-1504. doi:10.1136/bjophthalmol-2016-309946

11. Barbosa-Breda J, Gonçalves-Pinho M, Santos JV, et al. Trends in glaucoma surgical procedures in Portugal: a 16-Year Nationwide Study (2000-2015). J Glaucoma. 2018;27(8):682-686. doi:10.1097/ IJG.0000000000001011

12. Murphy C, Ogston S, Cobb C, MacEwen C. Recent trends in glaucoma surgery in Scotland, England and Wales. $\mathrm{Br} J$ Ophthalmol. 2015;99(3):308-312. doi:10.1136/bjophthalmol-2013-304465

13. Lang SJ, Wenzel M, Böhringer D, Reinhard T. Systematische Analyse der Krankenhausqualitätsberichte im Hinblick auf die Versorgung der Bevölkerung mit Kataraktoperationen. [Systematic analysis of the annual quality reports of the Federal Joint Committee with regard to cataract surgery]. Klin Monbl Augenheilkd. 2014;231(11):1115-1119. German. doi:10.1055/s-0034-1383067

14. Bucher F, Daniel MC, Böhringer D, et al. [Scleral buckling surgery in Germany for rhegmatogenous retinal detachment: a spirit of the past or current practice?]. Klin Monbl Augenheilkd. 2020;237(6):780-786. German. doi:10.1055/a-1078-1378

15. Daniel MC, Böhringer D, Reinhard T, Lang SJ. [The role of hospitals in the treatment of patients with cataract in germany: systematic analysis of the quality reports of German hospitals for the years 2006 to 2016]. Klin Monbl Augenheilkd. 2019;236(8):964-968. German. doi:10.1055/a-0838-5734

16. Daniel MC, Böhringer D, Lapp T, et al. [Keratoplasty in Germany: systematic analysis of the quality reports of German hospitals between 2006 and 2017]. Klin Monbl Augenheilkd. 2020. German. doi:10.1055/a-1035-9442

17. EGS. European Glaucoma Society Guidelines. 5th ed. 2021. Available from: https://www.eugs.org/eng/guidelines.asp. Accessed June 28, 2021.

18. $\mathrm{R}$ Core Team. R: a language and environment for statistical computing. 2021. Available from: https://www.r-project.org/. Accessed June 28, 2021.

19. Szigiato A-A, Trope GE, Jin Y, Buys YM. Trends in glaucoma surgical procedures in Ontario: 1992-2012. Can J Ophthalmol. 2015;50(5):338-344. doi:10.1016/j.jcjo.2015.07.005 
20. Chauhan BC, O’Leary N, AlMobarak FA, et al. Enhanced detection of open-angle glaucoma with an anatomically accurate optical coherence tomography-derived neuroretinal rim parameter. Ophthalmology. 2013;120(3):535-543. doi:10.1016/j.ophtha.2012.09.055

21. DeVience E, McMillan BD, Gross RL. Screening for Primary Open-angle Glaucoma (POAG). Int Ophthalmol Clin. 2018;58 (3):1-9. doi:10.1097/IIO.0000000000000227

22. Day AC, Baio G, Gazzard G, et al. The prevalence of primary angle closure glaucoma in European derived populations: a systematic review. $\mathrm{Br} J$ Ophthalmol. 2012;96(9):1162-1167. doi:10.1136/ bjophthalmol-2011-301189

23. He M, Jiang Y, Huang S, et al. Laser peripheral iridotomy for the prevention of angle closure: a single-centre, randomised controlled trial. Lancet. 2019;393(10181):1609-1618. doi:10.1016/S0140-6736(18)32607-2

24. Latina MA, Sibayan SA, Shin DH, et al. Q-switched 532-nm Nd: yAGlaser trabeculoplasty (selective laser trabeculoplasty): a multicenter, pilot, clinical study11Dr. Mark A. Latina has financial interest in this technology. Ophthalmology. 1998;105(11):2082-2090. doi:10.1016/S0161-6420(98)91129-0

25. Nagar M, Ogunyomade A, O'Brart DPS, et al. A randomised, prospective study comparing selective laser trabeculoplasty with latanoprost for the control of intraocular pressure in ocular hypertension and open angle glaucoma. Br J Ophthalmol. 2005;89(11):1413-1417. doi:10.1136/bjo.2004.052795
26. Gazzard G, Konstantakopoulou E, Garway-Heath D, et al. Selective laser trabeculoplasty versus eye drops for first-line treatment of ocular hypertension and glaucoma (LiGHT): a multicentre randomised controlled trial. Lancet. 2019;393(10180):1505-1516. doi:10.1016/S0140-6736(18)32213-X

27. Chou J, Turalba A, Hoguet A. Surgical innovations in glaucoma: the transition from trabeculectomy to MIGS. Int Ophthalmol Clin. 2017; 17 .

28. Fingeret M, Dickerson JE. The role of minimally invasive glaucoma surgery devices in the management of glaucoma. Optom Vis Sci. 2018;95(2):155-162. doi:10.1097/OPX.0000000000001173

29. Schlenker MB, Gulamhusein H, Conrad-Hengerer I, et al. Efficacy, safety, and risk factors for failure of standalone $\mathrm{Ab}$ interno gelatin microstent implantation versus standalone trabeculectomy. Ophthalmology. 2017;124(11):1579-1588. doi:10.1016/j.ophtha.2017.05.004

30. Basílio AL, Moura-Coelho N, Passos I, et al. XEN ${ }^{\circledR}$ implant and trabeculectomy medium-term quality of life assessment and comparison of results. Int $J$ Ophthalmol. 2018;11(12):1941-1944. doi:10.18240/ijo.2018.12.11

31. Marcos Parra MT, Salinas López JA, López Grau NS, et al. XEN implant device versus trabeculectomy, either alone or in combination with phacoemulsification, in open-angle glaucoma patients. Graefes Arch Clin Exp Ophthalmol. 2019;257(8):1741-1750. doi:10.1007/ s00417-019-04341-y
Clinical Epidemiology

\section{Publish your work in this journal}

Clinical Epidemiology is an international, peer-reviewed, open access, online journal focusing on disease and drug epidemiology, identification of risk factors and screening procedures to develop optimal preventative initiatives and programs. Specific topics include: diagnosis, prognosis, treatment, screening, prevention, risk factor modification, systematic reviews, risk \& safety of medical interventions, epidemiology \& biostatistical methods, and evaluation of guidelines, translational medicine, health policies \& economic evaluations. The manuscript management system is completely online and includes a very quick and fair peer-review system, which is all easy to use.

\section{Dovepress}

